\title{
Sound Banks - a Priceless Aid in Contemporary Music Writing
}

\author{
CĂTĂLIN RĂSVAN \\ National University of Music Bucharest \\ ROMANIA*
}

\begin{abstract}
Sound banks are collections of sound samples from musical instruments of the symphonic orchestra, traditional instruments from various areas of the world and sounds of virtual devices, such as synthesizers, which are increasingly present in contemporary musical creations. Sound banks are loaded in a device called sampler, which can edit and play them. The article describes analog and especially virtual samplers, complex devices that can store or play sounds from specific libraries of sound banks. It also defines and catalogs the main types of digital virtual instruments (that include traditional symphonic orchestra instruments, ones with modern electronic instruments/percussion instruments, and ethnic collections for various geographic areas. Our research on digital applications used in music writing relies on 20 years of experience. Currently, applications are valuable tools for composers and musicians, and for everyone in the contemporary music industry. In 2006, I created the first collection of sound banks made in Romania "The Essence of Panflute", library containing sound samples 583, grouped in 33 virtual instruments. This is the most complex virtual version of the Romanian pan flute, played by the renowned Cătălin Tîrcolea. The library is designed and edited by Cătălin Răsvan, for the company S.C. Canira Music Internațional. This collection of sound banks presents in minute detail the laborious process of recording and editing this virtual library. "The Essence of Panflute" has seen international acclaim, is distributed by the German company Best Service, one of the major companies in the world, was reviewed in the most prestigious magazine in this field, Sound on Sound, and has opened the door for current/future creators of music. We hope that it is only the beginning for our work in the research and development of digital virtual sound, which is a special category for the instruments in our country.
\end{abstract}

Keywords: Sound banks, digital techniques, virtual instruments, sound samples, distinct category.

\section{Introduction}

Sound banks are collections of sound samples (sound files) that can be loaded and played by a device called sampler ${ }^{1}$.

\footnotetext{
*loecata@yahoo.com

${ }^{1}$ A sampler is an electronic musical instrument, having its own RAM and containing multiple recordings (samples) of different sounds for musical instruments;

https://en.wikipedia.org/wiki/Sampler_(musical_instrument)
} 
The file is a digital recording of both sounds produced by electronic musical instruments and of natural sounds. The most know sound file formats are Wav fille (on PC) and AIF (on MAC). There are compressed audio files (.mp3), which lack in quality compared to uncompressed ones. For each sound in the range of a musical instrument, a sound file is included. These files, loaded in the sampler are laid out so that each key corresponds in frequency with the sound that is recorded and stored in the collection. For instance, the file with the sound having the frequency C3 (Do 3, $130.81 \mathrm{~Hz}^{2}$ ), will be placed on the key for C3.

By definition, the sampler is an electronic musical instrument that can store, play and edit sound samples, organized by certain criteria. The sampler is a useful device for musical creation, and it can use sound banks. It allows the sounds included in sound libraries to be created, stored, organized and used. There are two types of sampler: Hardware and Software. A hardware sampler is an actual device that has its own RAM, while the software one is a computer simulation of the actual device. Currently it can be said that there is no difference in quality between the two, considering the development of computers. By its design, the sampler can have an infinity of sounds, which makes it next to indispensable for a modern composition. The best known hardware samplers were (QASAR M8 - Fairlight Instruments, Fairlight - CMI, Emulator I,II and III manufactured by E-mu Systems, Roland SP808, Roland SP-505, Roland SP-303, Roland SP-202 - Roland, Mirage - Ensoniq, Korg and Kurzweil), Akai series S and Z, and software samplers (Giga Sampler, Giga Studio - Nemesys, HALion - Steinberg, Media Technologies GmbH, KONTAKT - Native Instruments GmbH, Sample tank - IK Multimedia. Software samplers have the advantage of running on a computer. Modern computers include strong processors, a lot of RAM and hard drives with extensive data storage capacity, allowing sampler software to run as well or even better than hardware samplers. This has been achieved in time, as computer technology has grown exponentially.

The sound banks that are made to be used in a sampler are divided into several categories. The largest category includes collection of instruments from the symphonic orchestra. Many companies have released products that are representative for this category, because such products are preferred by soundtrack scoring composers, due to their timbral particulars, the versatility and complexity of the component instruments, and are probably the most widely used sound banks. Many companies have released such libraries, but only some of them have become famous and appreciated worldwide. The best known and most widely used are: Miroslav Philharmonik, Peter Siedlaczek

\footnotetext{
${ }^{2}$ According to the site:

http://ro.wikipedia.org/wiki/\%C3\%8En\%C4\%83l\%C8\%9Bimea_sunetelor, accessed on 3.04.2018.
} 
Advanced Orchestra, Gary Garritan Personal Orchestra, Sonivox Complete Symphonic Collection, The Vienna Symphonic Library, HALion Symphonic Orchestra, E-MU's Modern Symphonic Orchestra, MOTU Symphonic Instrument (MSI), East West/Quantum Leap Symphonic Orchestra, 8 Dio Adagio, Agitato and Adagietto, Cage Bundle or the renowned Orchestral Tools with its products Berlin Brass, Berlin Woodwinds, Berlin Brass, and Berlin Percussion.

Another important category consists of traditional instruments sound banks. I would mention here, first of all ETHNO WORLD, created by composer Marcel Barsotti, who has written the score for 80 motion pictures. The library contains about 10 GB (14000 sound samples organized in 200 instruments, recorded under professional conditions). These are grouped in bowed string instruments, plucked string instruments, keyboard instruments, woodwinds, brass, percussion and vocal parts from various geographic zones. The collection is accompanied by the sampler Kontakt Player, allowing each instrument to be played in any tonality, using the Time Machine 2 technology. The library includes an impressive number of instruments: Tibetan bells, kantele (similar to a dulcimer), Irish flute, saron (a small percussive instruments, with plates laid in a single row, similar to the xylophone), saz (a plucked string instrument), santor (similar to the lute), military bass drum, angklung (percussion instrument made of bamboo tubes), Egyptian violin, erhu, gaohu (bowed string instruments), armonium, bouzouki (Greek plucked string instrument), hulusi (a wind instrument), dung (telescopic wind instrument (used in Tibetan sacred ceremonies), cajon (a string percussion instrument), balaphone (percussion instrument similar to the portable marimbaphone, without resonance cylinders), duduk (folk woodwind instrument specific to the peoples of the Caucasus), dvojacka (a kind of twin flute), hotchiku (a wind instrument made of bamboo), shakuhachi (a folk flute specific to traditional Japanese music), fujara (a large whistle), Ciaramella (a folk flute with double reed, similar to the zurna).

The library is released as VST 2.4, AAX and ASIO for Windows and VST, Audio Units, AAX, Core Audio, for MAC. The collection Ethno World 5 also includes three of the 43 pan flute variants from the Romanian collection The Essence of Panflute, released by S. C. Canira Music International S.R.L., which I coordinated as director. The proposal to include the two instruments in the above-mentioned collection (which was an honor and a confirmation of the product made by our company) came from the renowned German company Best Service GMBH. Other libraries in this category I would like to mention are Conexion Latina released by Future Loops, or the famous Heart of Asia and Heart of Afrika released by Spectrasonics.

Another category of sound banks are percussion instruments. Most companies in this industry have released such collections. The German Native 
Instruments $\mathrm{GmbH}$ has created a virtual instrument, Battery, which has reached its version 4. It is a sampler specializing in percussion instruments. It includes almost all categories of instruments, both natural and electronic, some coming from famous digital drum machines. The percussion instrument kits are organized in distinct categories.

The first category is called Acoustic Kits, and includes five kits: Full Jazz Kit, Heavy Rock Kit - Multi Mic, Pop Kit, Rock Kit - Multi Mic and Tight Kit. These are acoustic drum kits, recorded under professional conditions, with sounds that are appropriate for jazz, rock and pop. The second category, Production Kits, includes eight hybrid percussion instruments obtained by combining electronic and acoustic instruments: Dragon Kit, Dub Remix Kit, Elektro Acoustik Kit, GVA Kit, Hardkore Gothik Kit, Live Scrapyard Kit, NuPop Kit and Studio Gong Kit. The third category, Percussion Kits, includes five kits of percussion instruments that are specific to geographic areas (Africa, Asia and South America): East Asian Kit, Marching Band Kit, North Indian Kit, West African Kit and World Music Kit. The last two categories, Synthetic Kits and Special Kits consist of electronic and atmospheric percussion instruments and include the kits Glitch Kit, Mega Synthetic Kit, Orgami Kit, Robati Kit, Sintheti Kit, Vrtrel Kit, Wooden Clog Kit, Armageddon Kit, Berlin Headquarters Kit, Factory Kit, Microwave Kit, Noise Kit and Prepared Percussion Kit. Due to the variety of its sounds, Battery 4 is one of the most widely used collection of percussion instruments. Another virtual percussion instrument, called STYLUS RMX TM - REAL TIME GROOVE MODULE202 release by Spectrasonics ${ }^{3}$ is considered one of the most complex virtual rhythm modules. It runs on Windows and MAC, as VST or AAX. Due to the technologies Groove Control ${ }^{\mathrm{TM}}$ and Advanced Groove Engine (S.A.G.E. ${ }^{\mathrm{TM}}$ ), each of the included loops can be edited as audio file (tempo, pitch, duration) in the host application. The virtual device includes 7 GB of sound loops and can be expanded to 13 GB if the user acquires the five extensions: BackBeat, Retro Funk, Liquid Grooves, Burning Grooves, Metamorphosis. The musician can easily access each element of a loop included in the project using the Slice Menu. This makes it possible to create new rhythms consisting of the individual elements of a rhythm loop that is included with the module. Starting with version 1.7 it includes a new technology, Time, allowing to change the time signature of an audio loop. Worldwide, this is an innovation achieved by the hard work of the engineers from Spectrasonics under the guidance of the manager, sound designer Eric Persing. Due to the complex options for editing, fast workflow and quality, this sound module is used by many artists, such as Pat Metheny Group, Bjork, Peter Gabriel, Herbie Hancock, U2, Elton John, Pink, The Dave Matthews Band and Shakira and many others.

\footnotetext{
${ }^{3}$ http://www.spectrasonics.net/companyinfo/users.php, accessed on 29.03.2018.
} 


\section{Personal Contribution in taking advantage of the Personal Performance}

The Essence of Panflute is an ambitious project to create a new collection of sound banks that contains the wondrous Romanian instrument - the pan flute - and it was created 2006, making the most of the instrument's expression possibilities. The basic idea of the project was to capture the pan flute at exceptional quality, with regard to both the studio equipment and the live performance by Cătălin Tîrcolea. The musical production was designed and carried out entirely under my supervision (together with my wife Nicoleta Răsvan) by S.C. Canira Music International S.R.L., in which I was the director. Personally, I handled the full design of the product, the recording and editing of the sound material. The General MIDI bank that comes with digital synthesizers includes a pan flute preset, but a connoisseur of the instrument's technical possibilities will never be satisfied with that one preset. Knowing the market's requirements and the limited offer for this, I got the idea of achieving this difficult task. I was aware that hard and long work would follow, I knew that all efforts would be worth it, because when the project was finished the country's reputation would stand to gain. None of the established sound bank production companies had the idea to release a pan flute at the highest standards. It is no small feat to complete an idea and end up with a quality product, made in România.

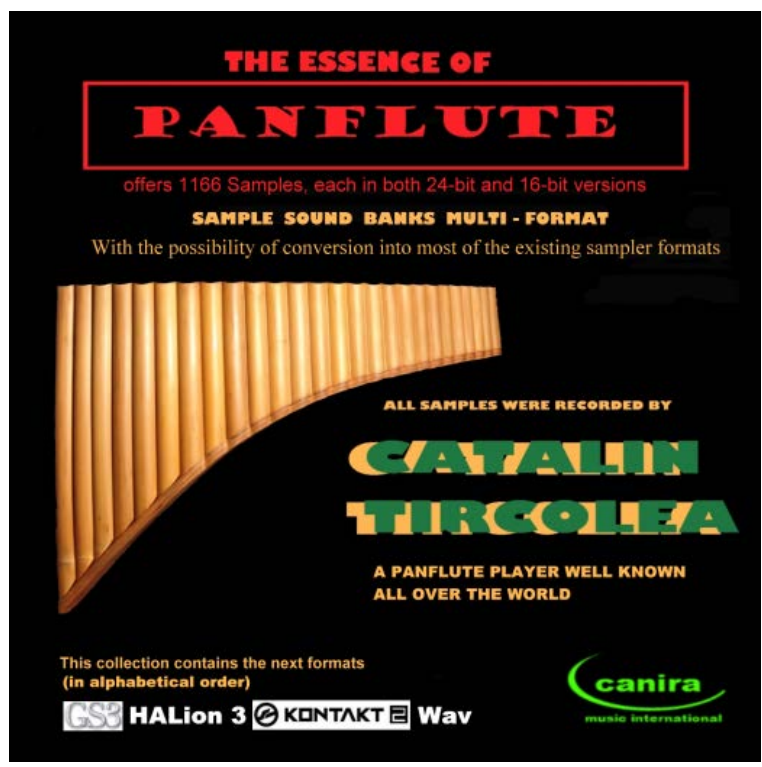

Fig. 1 Front cover of the DVD for the collection "The Essence of Panflute" 


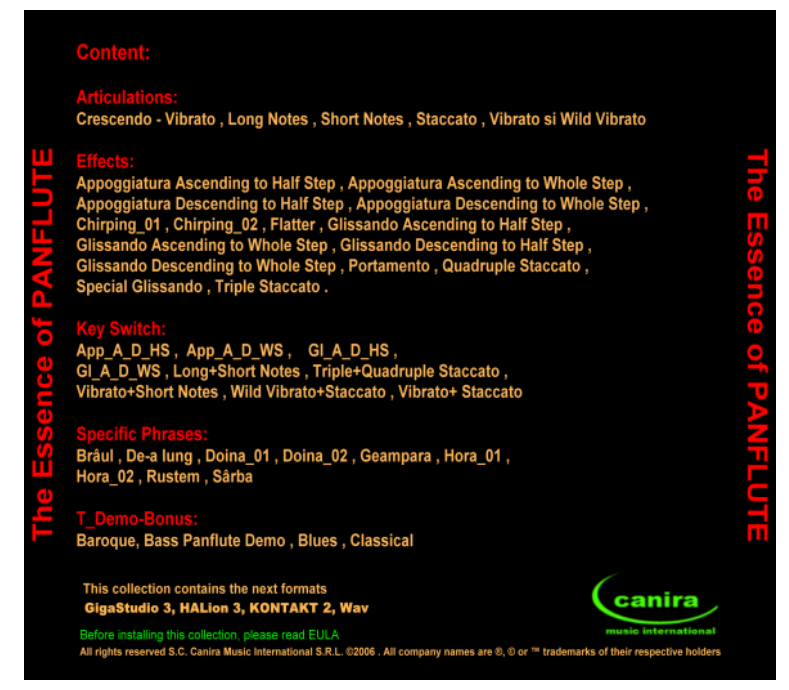

Fig. 2 Back cover DVD for the collection "The Essence of Panflute”

The first stage in the production process was the recording, which took place using the German application Cubase, from January until the end of February. This involved almost daily recordings and added up to hundreds of hours of recording. The capture was done in a small, soundproof booth (4 square meters). For the stereo recording of the sound material, we used two microphones (specializing in the high frequencies). These are the models $\mathrm{C}$ 3000B and C 4000 B of the German AKG. Over 3000 sound samples were recorded (for the selection of the best versions), which were in the end selected down to 583. Choosing the most representative sound samples that fully met the performance criteria was a first decisive stage in the musical production and it was done by hearing the samples together with the performer.

The second stage of the library production process was editing and processing the recorded material. This involved almost six months of exhausting work for editing and processing (hundreds of hours of work, sometimes even eleven hours per day, with no days off). From the raw product - the recording - to the end product, the way was very long. The processed followed an algorithm consisting of several stages. The first was hearing and picking the best samples. Then the samples were cut and cleared of unwanted sounds (produced during the recording). There are invariably such situations. The sound engineer must decide whether a sound can be cleaned up under optimal conditions without the process being noticeable. I used the virtual sound effect Redunoise by Voxengo which is able to analyze a portion of background noise, and then remove it from the sound sample without affecting the musical part. The following stage was tuning the instrument to $440 \mathrm{HZ}$. Any sound bank is tuned to the same frequency, and so the one included in the 
project had to meet the same standards. As it is known, the pan flute is an untempered instrument. While during recording I noticed that some sounds were played slightly flat or sharp, I knew that this could be corrected by processing. Thus I listened to each sound and brought it to the desired frequency.

The third stage was the most difficult part of the editing process and consists of determining the musicality of the instrument, in that, while the user operates with pan flute sounds, this is controlled using an electronic keyboard (a different playing technique than the natural instrument). For this reason, each recording must be heard hundreds of times. One must also check the attack of each sound in the bank, by playing different musical parts at different tempos and styles. Many times there are sounds that lose the natural sound of the instrument at a faster tempo. Such sounds are marked and then the start of the sample is edited in a special audio editor, at the level of milliseconds. It's like a "painting" of the sound start to obtain an attack that is as close to the real one as possible. I used the WaveLab audio editor of the German company Steinberg, which has been an invaluable help. After editing, the bank needed to be loaded back into the sampler to check the result. Many times, for a single bank including around thirty samples, the process had to be repeated at least ten times.

I tried hard to work perfectly in this stage, because I knew there were collections, some of them well known that had this defect. I also knew that this was the first product of its kind coming from Romania and it had to be impeccable. Any user is much more careful and curious when a product does not come from a well-known source with established tradition in the field. I only had the option to have a perfect product or give up, so I worked very hard to complete this editing stage impeccably. After almost three months, I finally reached the conclusion that the product was technically perfect and could measure up with the most renowned sound bank collections. The Essence of Panflute is made in three of the most widely used sampler formats, namely: HALion, Gigastudio, and KONTAKT. I initially made the prototype in HALion format, and then I converted the banks to the other two formats. For conversion I used a professional application, Extreme Sample Converter 3, released by a well-known Polish programmer, Wlodzimierz Grabowski. I had some correspondence with the programmer, as I had discovered a bug of the application in the conversion from HALion to Giga Studio. Wlodzimierz thanked me, as he hadn't noticed it, and fixed it. At that time I had the banks in all the three desired formats.

For the international recognition of copyright I described the content of the library in detail and filed with O.R.D.A. (Romanian Copyright Office). I have the hope and conviction that the road I have opened will be followed by other Romanian creators of sound banks. This is why I attach the form I filled 
in, as a model. Because this is an official document I reproduced it identically, even though the text includes repeated words (e.g. includes). „The Essence of Panflute" is a collection of samples WAWE SOUND format. These are arranged in directories, named as follows: "24 Bit Panflute Content" and "16 Bit Panflute Content“, „24 Bit Key Switch Panflute Content“ and “16 Bit Key Switch Panflute Content”.

The directories " 24 Bit Panflute Content" and "16 Bit Panflute Content" are in turn organized in 34 Sub-directories, in which the 583 sound files (WAWE SOUND) are placed, named and grouped as follows: "Appoggiatura Ascending to Half Step", "Appoggiatura Ascending to Whole Step", "Appoggiatura Descending to Half Step”, "Appoggiatura Descending to Whole Step”, "Baroque”, "Bass Panflute Demo", "Blues”, "Brâul”, "Chirping_01”, “Chirping_02”, “Classical”, "De-a lung”, “Doina_01”, "Doina _02”, "Flatter” , "Geampara”, "Glissando Ascending to Half Step", "Glissando Ascending to Whole Step", "Glissando Descending to Half Step", "Glissando Descending to Whole Step”, “Hora _ 01”,"Hora _ 02”, “Long Notes”, "Portamento”, "Quadruple Staccato", "Rustem”, "Sârba”, "Short Notes”, "Staccato", "Triple Staccato", "Quadruple Staccato", "Vibrato", and "Wild Vibrato". The directories "24 Bit Panflute Content" and "16 Bit Panflute Content" include the 583 sound samples at 24 and 16 bit, at $44100 \mathrm{~Hz}$. The directories "24 Bit Key Switch Panflute Content” and "16 Bit Key Switch Panflute Content” were created only for the Kontakt sampler, due to its particular features.

After six months of hard work, the "miracle" I wanted so much happened. I contacted the renowned German company that produces and sells sound banks, Best Service. Following my request for them to become international distributors of the collection The Essence of Panflute, the manager of the company, Mr. Klaus Kendler, answered. He was downright enthusiastic and agreed to become the official distributor of the product. When I created The Essence of Panflute, I intended for it to be a very musical library, including most of the usual articulations of the pan flute, but I also wanted it to include musical phrases from Romanian folklore, wanting the beauty of Romanian folk music to be known abroad.

Soon there were several articles about The Essence of Panflute in the most important magazines in this industry. Among these I will mention Sound on Sound, one of the most reputable publications for musical applications, in May 2007 and the article in Sound \& Recording of February 2007. Sound on Sound had a lot of praise for The Essence of Panflute, rating it five stars for its production and price, which is the highest score for such a product. The article in Sound on Sound of May 2007 gave me the certainty that I had achieved my goals, stating that: "This panflute is mapped chromatically in concert pitch over a range of nearly three and a half octaves (D3 - G6). [...] Other effects include 'special glissando' (a fast sweep up, reminiscent of a slide-whistle) and 
a set of bird-like calls, tweets and flutings. There are also many licks and phrases ready to insert in your scores: extremely rapid, virtuosic rhythmic passages, mournful, soulfully-played rainforest laments.” This was the first Romanian product reviewed in a magazine of this level, and I am sure that it could open a gate for Romania to the world. The article can be found in the magazine or directly on the Internet ${ }^{4}$. In September 2010, version five of the renowned sound library Ethno World, released by the well-known German company Best Service GmbH. The collection includes 3 of the 43 presets from The Essence of Panflute, also specified in the presentation manual. This is a great achievement, as it is an acknowledgement of the quality of The Essence of Panflute. Here is the presentation text from the Ethno World 5 manual: "The Pan Flute Canira Instrument is from the Essence of Panfute album made by Canira Music International from Romania, in the original conception of the musician Catalin Rasvan licenced by the Essence of Panflute collection, produced by S.C. Canira Music International S.R.L.”; “This panflute is mapped chromatically in concert pitch over a range of nearly three and a half octaves, from D3 to G6 [...]. Other effects include 'special glissando' (a fast sweep up, reminiscent of a slide-whistle) and a set of bird-like calls, tweets and flutings. There are also many licks and phrases ready to insert in your scores: extremely rapid, virtuosic rhythmic passages, mournful, soulfully-played rainforest laments, Eastern European". The above quote is from the article in Sound \& Recording, published in May 2007.

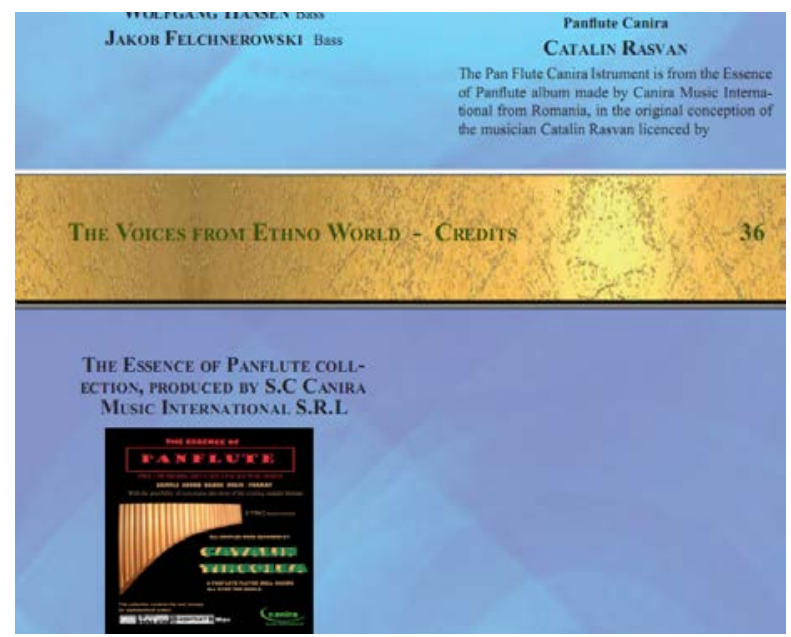

Fig. 3 Image from inside the Ethno World 5 manual

\footnotetext{
${ }^{4}$ http://www.soundonsound.com/sos/may07/articles/sampleshop05 07.htm
} 
The essence of Panflute is not just a music library, but also a series of unique emotional states of the performing artist, and tries to synthesize his own personal performance fingerprint. A performance fingerprint is the signature of the performing artist that can be found and used in sound bank collections. Achieving it depends on the cooperation of the performing artist with the musical producer. The main feature of a musical production is unique performance, and this is why the two must choose the best musical moments. Later, such moments will represent the musician's performance vision. Sound banks consider two essential aspects: studio expression (studio recording of the sounds emitted by a performer) and live performance particulars (taken from stage performances). In both cases, regardless of the chosen approach (elementary or contextual sound, phrase, pitch, duration, intensity or timbre), the producer and the performer have the duty to choose the brightest examples of performance. Recording phrases, motifs and musical periods is a complex product of selection from the most representative musical moments, with a decisive role in achieving a quality musical product.

\section{Conclusions}

An important feature of the last decade of the 20th century was the widescale use of digital means in all sectors. Currently, it is hard to imagine an industrial, economic or medical activity without computer assistance. There is a wide variety of specialized software, created to optimize the planning and activity of various social and economic fields. Many Romanian companies operate in the systematization of industrial activities, assisted by complex computer networks, and there is no field of activity without complex computer networks.

In order to fully take advantage of the digital system, the musician must gain good knowledge of digital devices, virtual digital instruments (digital audio workstation, synthesizer, sampler, and sound banks). The effort to learn the digital technology will be greatly rewarded by the excellent results obtained in sound. A musical digital sample is a recording of one or several sounds emitted by a musical instrument, a phrase or period to be then used as a component of a sound bank. As the crown jewel of a sound bank, the musical phrase must be recorded repeatedly at varied tempos, in distinct times, days, seasons, personalizing the uniqueness of a phrase, dressed in a well-determined temporal attire.

The collection I have created, "The Essence of Panflute" contributes to enriching the sound banks in the international music field. The basic idea of th project was to capture the pan flute at exceptional quality, both in studio recording and in performance particulars (live) of the performer Cătălin Tîrcolea. 


\section{References}

Barsotti, M. (2010), Virtual Ethno Instruments \& Voices, User Guide. Best service.

Klag, M.\&Bachmann, M.R.C.\& Bischoff, H. et al (2018). (C) Steinberg Media Technologies GmbH, HALion_6.2.0_en-US_2018-11-15

Klag, M.\& Ruf, M. \& Bachmann, M.R.C. \& Bischoff, H. et al (2014). HALion Symphonic Orchestra, Operation Manual, pdf /HALion_Symphonic_Orchestra (C) Steinberg Media Technologies GmbH. Retrieved from http: //download. steinberg. Net / downloads software/VST_SIS_HALion_Symphonic_Orchestra/HALion_Symphonic_Orchestra_Operati on_Manual_en_ja.pdf

Kontakt 5 Library Manual (2017). NATIVE INSTRUMENTS Gmbh.

Miroslav Philharmonik 2 The New orchestra with legendary soul (2017), IK Multimedia Production srl. Retrieved from https://www.ikmultimedia.com/products/philharmonik2/.

Morgenstern, J. Hanley, A. (2017). Kontakt 5, Manual. Software version: 5.6.8.

Native Instruments, GmbH, Best Service Complete Classical Collection KP2 Manual.

Răsvan, C., The Essence of panflute (2006), Register_Content_ Install Notes, Canira Music International S.R.L. 